\title{
Dietary magnesium intake and fracture risk: data from a large prospective study
}

\author{
Nicola Veronese ${ }^{1,2} w_{\dagger}$, Brendon Stubbs ${ }^{3,4} \dagger$, Marco Solmi $^{2,5}$, Marianna Noale $^{1}$, Alberto Vaona ${ }^{6}$, \\ Jacopo Demurtas ${ }^{7}$ and Stefania Maggi ${ }^{1}$ \\ ${ }^{1}$ National Research Council, Neuroscience Institute, Aging Branch, 35128, Padova, Italy \\ ${ }^{2}$ Institute for Clinical Research and Education in Medicine (IREM), 35128, Padova, Italy \\ ${ }^{3}$ Physiotherapy Department, South London and Maudsley NHS Foundation Trust, Denmark Hill, London SE5 8AZ, UK \\ ${ }^{4}$ Health Service and Population Research Department, Institute of Psychiatry, King's College London, De Crespigny Park, \\ London SE5 8AF, UK \\ ${ }^{5}$ Department of Neurosciences, University of Padova, 35128, Padova, Italy \\ ${ }^{6}$ Primary Care Department, Azienda ULSS20 Verona, 37122, Verona, Italy \\ ${ }^{7}$ Primary Care Department, Azienda USL Toscana Sud Est, 58042, Grosseto, Italy \\ (Submitted 3 December 2016 - Final revision received 6 April 2017 - Accepted 10 April 2017-First published online 20 June 2017)
}

\section{Abstract}

Research considering the relationship between dietary $\mathrm{Mg}$ and osteoporosis as well as fractures are sparse and conflicting. We therefore aimed to investigate $\mathrm{Mg}$ intake and the onset of fractures in a large cohort of American men and women involved in the Osteoarthritis Initiative over a follow-up period of 8 years. Dietary Mg intake (including that derived from supplementation) was evaluated through a FFQ at baseline and categorised using sex-specific quintiles (Q); osteoporotic fractures were evaluated through self-reported history. Overall, 3765 participants (1577 men; 2071 women) with a mean age of 60.6 (sD 9.1) years were included. During follow-up, 560 individuals (198 men and 368 women) developed a new fracture. After adjusting for fourteen potential confounders at baseline and taking those with lower Mg intake as reference (Q1), men (hazard ratio (HR) 0.47; $95 \%$ CI 0.21, 1.00, P=0.05) and women (HR 0.38; $95 \%$ CI 0.17 , $0.82, P=0.01)$ in the highest quintile reported a significantly lower risk for fracture. Women meeting the recommended Mg intake were at a $27 \%$ decreased risk for future fractures. In conclusion, higher dietary Mg intake has a protective effect on future osteoporotic fractures, especially in women with a high risk for knee osteoarthritis. Those women meeting the recommended Mg intake appear to be at a lower risk for fractures.

Key words: Magnesium: Fractures: Osteoporosis: Epidemiology

$\mathrm{Mg}$ is the fourth most abundant cation in the body and plays a pivotal role in many of its functions, being involved in more than 300 enzymatic reactions ${ }^{(1,2)}$.

Several observational studies have demonstrated that low $\mathrm{Mg}$ intake is associated with a higher risk for several CVD and metabolic diseases, including coronary artery disease ${ }^{(3)}$, hypertension $^{(4)}$, the metabolic syndrome ${ }^{(5)}$ and diabetes ${ }^{(6)}$.

Although about $60 \%$ of total $\mathrm{Mg}$ is stored in the bone $\mathrm{f}^{(7)}$, the role of this cation in bone diseases and osteoporosis is still unclear. In a recent systematic review and meta-analysis, higher dietary $\mathrm{Mg}$ intake was not associated with decreased fracture risk in prospective studies ${ }^{(8)}$. In the largest prospective study included in this meta-analysis ${ }^{(9)}$, the authors found that $\mathrm{Mg}$ intake higher than the RDA resulted in a higher risk for fractures, probably related to more physical activity and falls ${ }^{(9)}$. A similar result was obtained by another large study in Swedish people ${ }^{(10)}$.

These findings are, however, surprising as in cross-sectional studies there was a significant association between higher $\mathrm{Mg}$ intake and bone mineral density (BMD) ${ }^{(8)}$. The beneficial role of $\mathrm{Mg}$ in inflammation ${ }^{(11)}$ and oxidative stress ${ }^{(12)}$, two remarkable risk factors for osteoporosis, is well-known. Moreover, $\mathrm{Mg}$ is contained in green vegetables, nuts, cereals and other components of a Mediterranean diet that seems to have an important protective effect on bone fractures in women ${ }^{(13)}$.

Because of these conflicting results, we aimed to investigate the effect of higher $\mathrm{Mg}$ intakes on the onset of fractures in a large cohort of American men and women involved

Abbreviations: HR, hazard ratio; OAI, Osteoarthritis Initiative.

* Corresponding author: N. Veronese, fax +39 498211 218, email ilmannato@gmail.com

$\dagger$ These authors contributed equally to this work. 
in the Osteoarthritis Initiative (OAI) over a follow-up period of 8 years.

\section{Methods \\ Data source and subjects}

Data were obtained from subjects enrolled in the OAI database, which is available for public access at http://www.oai.ucsf.edu/. Specific data sets used are those recorded during baseline and screening evaluations (V00) and those from each database reporting data on fractures until 96 months from baseline (V10). All participants in this study were recruited as part of the ongoing, publicly and privately funded, multicentre, and longitudinal OAI study. Patients at a high risk for knee osteoarthritis were recruited from four clinical sites in the USA (Baltimore, MD; Pittsburgh, PA; Pawtucket, RI; and Columbus, OH) between February 2004 and May 2006.

All of the participants provided written informed consent. The OAI study protocol was approved by the institutional review board of the OAI Coordinating Center, University of California at San Francisco.

\section{Exposure}

Dietary Mg intake was obtained through a FFQ recorded during the baseline visit of the OAI. As this questionnaire included data on $\mathrm{Mg}$ supplementation, this intake was also calculated. $\mathrm{Mg}$ intakes were computed as residuals from the regression model, with total energetic intake as the independent variable (residual method) ${ }^{(14)}$. The entire cohort was divided into quintiles (Q) of $\mathrm{Mg}$ intake according to sex using 205, 269, 323 and $398 \mathrm{mg} / \mathrm{d}$ for men and 190, 251, 306 and $373 \mathrm{mg} / \mathrm{d}$ for women.

\section{Outcomes}

The presence of fractures at baseline and during follow-up was obtained through self-reported history of fractures at the most common sites for osteoporotic fractures, that is, the hip, spine and the forearm. As the hip, spine and the forearm are the most common sites of osteoporotic fractures, these outcomes were initially evaluated separately; although, for convergence problems, analyses for the hip ( $n$ 44) and spine $(n$ 77) were not reliable.

\section{Covariates}

A number of variables were identified from the OAI data set to explore the relationship between dietary $\mathrm{Mg}$ intake and incident fractures. These included the following: (1) race defined as 'whites' $v$. others; (2) smoking habits as 'previous/current' $v$. never; (3) educational level categorised as 'college' $v$. others; (4) yearly income as $<$ or $\geq \$ 50000$ and missing data; (5) BMI, measured by a trained nurse; (6) comorbidities assessed using the modified Charlson co-morbidity score, with higher scores indicating an increased severity of conditions ${ }^{(15)}$; (7) daily intake of vitamin $\mathrm{D}, \mathrm{Ca}, \mathrm{K}$ (from food and from supplements) and total energy intake; and (8) physical activity, evaluated using the Physical Activity Scale for the Elderly, a validated scale for assessing the physical activity level in the elderly. The scale covers twelve different activities including walking, sports and housework, and is scored from 0 upwards, without a maximum score $^{(16)}$. Moreover, data regarding the use of drugs positively affecting bone (teriparatide, bisphosphonates and hormones) were also recorded.

\section{Statistical analyses}

As $\mathrm{Mg}$ intake was significantly different between men and women, as was the incidence of fractures during follow-up ( $P<0.0001$ for both comparisons), and as the interaction between dietary $\mathrm{Mg}$ intake and sex in predicting fracture onset at follow-up was significant $\left(P_{\text {for interaction }}=0 \cdot 04\right)$, all findings are reported by sex.

For continuous variables, normal distributions were tested using the Kolmogorov-Smirnov test. The data are shown as means and standard deviations for quantitative measures, and as frequency and percentages for all discrete variables by dietary $\mathrm{Mg}$ intake at baseline. For continuous variables, differences between the means of the covariates by quintiles of dietary Mg intake were analysed using an ANOVA; the $\chi^{2}$ test was applied for discrete variables. Bonferroni correction was used in all analyses. Levene's test was used to test the homoscedasticity of variances and, if its assumption was violated, Welch's ANOVA was used.

Multivariate Cox regression models were studied using total $\mathrm{Mg}$ intake (sum of $\mathrm{Mg}$ from supplements and from foods) at baseline as exposure, categorised as quintiles and as outcome incident fractures at follow-up. Factors that reached a statistical significance between participants with osteoarthritis and those without or significantly associated with depressive symptomatology at follow-up (considering $P<0.05$ as statistically significant) were included. Multicollinearity among covariates was assessed using variance inflation factor, with a cut-off value of 2 as a reason for exclusion, but no variable was excluded owing to this reason. Data of Cox regression analysis were reported as hazard ratios (HR) with their 95\% CI. A similar analysis was run modelling total $\mathrm{Mg}$ intake as a continuous variable.

All analyses were performed using SPSS 21.0 for Windows (SPSS Inc.). All statistical tests were two-tailed and statistical significance was assumed for $P<0 \cdot 05$.

\section{Results}

\section{Study participants}

At baseline, among 4796 potentially eligible individuals, 243 reported unreliable data in the FFQ (i.e. $<2092 \mathrm{~kJ}(<500 \mathrm{kcal})$ or $>20920 \mathrm{~kJ}$ (>5000 kcal)), $788 \mathrm{had}$ a fracture at baseline, and 117 were lost at follow-up (i.e. did not have the first follow-up visit), leaving 3765 participants eligible for this research.

\section{Baseline analyses}

Overall, 3765 participants (1577 men; 2071 women) with a mean age of $60 \cdot 6$ (sD 9.1) (range: 45-79) years were eligible for 
Table 1. Participants' characteristics by baseline magnesium intake in men (Mean values and standard deviations; numbers and percentages)

\begin{tabular}{|c|c|c|c|c|c|c|c|c|c|c|c|}
\hline & \multicolumn{2}{|c|}{ Q1 (n 316) } & \multicolumn{2}{|c|}{ Q2 (n 314) } & \multicolumn{2}{|c|}{ Q3 (n 316) } & \multicolumn{2}{|c|}{ Q4 (n 315) } & \multicolumn{2}{|c|}{ Q5 (n 316) } & \multirow[b]{2}{*}{$P^{*}$} \\
\hline & Mean & SD & Mean & SD & Mean & SD & Mean & SD & Mean & SD & \\
\hline$M g$ from diet $(\mathrm{mg} / \mathrm{d})$ & 149 & 38 & 200 & 45 & 235 & 46 & 292 & 48 & 419 & 92 & $<0.0001$ \\
\hline Mg from supplementation (mg/d) & 13 & 29 & 38 & 45 & 61 & 45 & 65 & 45 & 69 & 43 & $<0.0001$ \\
\hline Total $\mathrm{Mg}$ intake $(\mathrm{mg} / \mathrm{d})$ & 161 & 34 & 239 & 18 & 299 & 16 & 359 & 22 & 491 & 87 & $<0.0001$ \\
\hline Age (years) & $60 \cdot 0$ & $9 \cdot 7$ & $59 \cdot 3$ & 9.4 & 60.5 & 9.4 & $62 \cdot 2$ & $9 \cdot 7$ & 60.9 & 9.4 & 0.002 \\
\hline \multicolumn{12}{|l|}{ Nutritional parameters } \\
\hline Energy intake (kJ/d) & 4431 & 1339 & 5569 & 1590 & 6335 & 1816 & 7297 & 1937 & 9519 & 2690 & $<0.0001$ \\
\hline Energy intake (kcal/d) & 1059 & 320 & 1331 & 380 & 1514 & 434 & 1744 & 463 & 2275 & 643 & $<0.0001$ \\
\hline Ca intake $(\mathrm{mg} / \mathrm{d})$ & 539 & 300 & 762 & 371 & 903 & 388 & 1078 & 463 & 1372 & 506 & $<0.0001$ \\
\hline $\mathrm{K}(\mathrm{mg} / \mathrm{d})$ & 1556 & 432 & 2076 & 513 & 2421 & 537 & 2965 & 592 & 4059 & 974 & $<0.0001$ \\
\hline Vitamin D intake (mg/d) & 147 & 129 & 289 & 193 & 397 & 192 & 455 & 210 & 538 & 242 & $<0.0001$ \\
\hline Alcohol intake (\% of energy) & $6 \cdot 8$ & $9 \cdot 1$ & $6 \cdot 8$ & 8.2 & 6.4 & 8.1 & $5 \cdot 8$ & $6 \cdot 8$ & 4.9 & $5 \cdot 7$ & 0.005 \\
\hline BMI $\left(\mathrm{kg} / \mathrm{m}^{2}\right)$ & 29.2 & $4 \cdot 3$ & $29 \cdot 2$ & 3.9 & $28 \cdot 7$ & $4 \cdot 1$ & $28 \cdot 4$ & 4.0 & $28 \cdot 6$ & $4 \cdot 2$ & 0.05 \\
\hline \multicolumn{12}{|l|}{ Demographics } \\
\hline White race & \multirow{2}{*}{\multicolumn{4}{|c|}{239}} & \multirow{2}{*}{\multicolumn{2}{|c|}{286}} & & & & & 0.005 \\
\hline$n$ & & & & & & & 272 & & \multicolumn{2}{|c|}{265} & \\
\hline$\%$ & \multicolumn{2}{|c|}{76} & 84 & & \multicolumn{2}{|c|}{91} & 87 & & \multicolumn{2}{|c|}{84} & \\
\hline Smoking (previous/current) & & & & & & & & & & & 1.00 \\
\hline$n$ & \multicolumn{2}{|c|}{159} & 16 & & \multicolumn{2}{|c|}{154} & 160 & & \multicolumn{2}{|c|}{163} & \\
\hline$\%$ & \multicolumn{2}{|c|}{51} & 53 & & \multirow{2}{*}{\multicolumn{2}{|c|}{49}} & 51 & & \multicolumn{2}{|c|}{52} & \\
\hline College & \multirow{2}{*}{\multicolumn{2}{|c|}{118}} & & & & & & & & & 0.56 \\
\hline$n$ & & & 12 & & \multicolumn{2}{|c|}{112} & 116 & & \multicolumn{2}{|c|}{112} & \\
\hline$\%$ & \multicolumn{2}{|c|}{37} & 38 & & \multicolumn{2}{|c|}{36} & 37 & & \multicolumn{2}{|c|}{35} & \\
\hline Yearly income $(<\$ 50000)$ & & & & & & & & & & & 0.69 \\
\hline$n$ & 207 & & 23 & & 23 & & 224 & & & & \\
\hline$\%$ & 68 & & 75 & & 74 & & 73 & & & & \\
\hline PASE (points) & 171 & 84 & 182 & 79 & 174 & 89 & 174 & 88 & 186 & 94 & 0.13 \\
\hline Medical conditions and medicatio & & & & & & & & & & & \\
\hline Charlson co-morbidity score & 0.43 & 0.89 & 0.41 & 0.90 & 0.41 & 0.89 & 0.42 & 0.93 & 0.43 & 0.98 & 1.00 \\
\hline$n$ & 2 & & 4 & & 6 & & 7 & & & & \\
\hline$\%$ & 0.6 & & 1.3 & & 1.5 & & $2 \cdot 2$ & & & & \\
\hline Bisphosphonates & & & & & & & & & & & 0.38 \\
\hline$n$ & 2 & & 7 & & 3 & & 7 & & & & \\
\hline$\%$ & 0.6 & & $2 \cdot 2$ & & 1.6 & & $2 \cdot 2$ & & & & \\
\hline
\end{tabular}

Q, quintile; PASE, Physical activity Scale for Elderly.

* $P$ values were calculated using the ANOVA for continuous and $x^{2}$ test for categorical ones, respectively. Bonferroni correction was applied for all comparisons.

inclusion in the current study. The mean intake of $\mathrm{Mg}$ was 295 (sD 116) mg/d, with 53 (SD 47) $\mathrm{mg}$ derived from oral supplementation. Only $27.0 \%$ of the whole cohort reached correspondent RDA (i.e. $420 \mathrm{mg}$ for men and 320 for women, respectively) ${ }^{(17)}$

The baseline characteristics by dietary Mg intake and by sex are summarised in Tables 1 and 2 . Independent of sex, those with higher Mg intake were more significantly old, white and had a significantly higher energy intake including a higher dietary intake of micronutrients ( $\mathrm{K}, \mathrm{Ca}$ and vitamin $\mathrm{D}$ ), but they consumed a significantly lower amount of alcohol than participants with lower $\mathrm{Mg}$ intake. Conversely, no significant differences emerged regarding the physical activity level and presence of comorbidities. Finally, men with higher $\mathrm{Mg}$ intake were significantly leaner than those consuming less $\mathrm{Mg}$ (Table 1). In women, individuals consuming more $\mathrm{Mg}$ were also more likely to be prescribed bisphosphonates than those consuming less $\mathrm{Mg}$, although this difference did not reach significance $(P=0.06)$. In the sample as a whole, only four participants used teriparatide, which may be due to the fact that people who already had a diagnosis of fractures were excluded.

\section{Follow-up analyses and incident fracture onset}

After a mean period of $6 \cdot 2$ years, 560 individuals ( 198 men and 362 women) developed a new fracture. As shown in Table 3, men (Q5 20; $95 \%$ CI 13, $27 v$. Q1 27; $95 \%$ CI 18, 36; Fig. 1(a)) and women (Q5 27; 95\% CI 20, $34 v$. Q1 31; $95 \%$ CI 23, 39; Fig. 1(b)) with higher $\mathrm{Mg}$ intake reported a significantly lower incidence of fractures compared with those having a lower Mg intake.

After adjusting for fourteen potential confounders at baseline and taking those with lower $\mathrm{Mg}$ intake as reference (i.e. those in Q1), men (HR 0.47; 95\% CI 0.21, 1.00, $P=0.05$ ) and women (HR $0.38 ; 95 \%$ CI $0.17,0.82, P=0.01$ ) in the fifth quintile reported a significantly lower risk for fracture (Table 3). As height is a better predictor than BMI for fractures ${ }^{(18)}$, in a secondary analysis, we introduced height in the fully adjusted model. Compared with subjects having a lower Mg intake, men in the fifth quintile reported a non-significant association with incident fractures ( $\mathrm{HR} 0.75 ; 95 \%$ CI $0.45,1.25, P=0.75$ ), whereas women with the highest $\mathrm{Mg}$ intake reported a significantly reduced risk for fractures (HR 0.47; $95 \%$ CI 0.33 , 0.68, $P<0.0001$ ). 
Table 2. Participants' characteristics by baseline magnesium intake in women

(Mean values and standard deviations; numbers and percentages)

\begin{tabular}{|c|c|c|c|c|c|c|c|c|c|c|c|}
\hline & \multicolumn{2}{|c|}{ Q1 (n 414) } & \multicolumn{2}{|c|}{ Q2 (n 411) } & \multicolumn{2}{|c|}{ Q3 (n 421) } & \multicolumn{2}{|c|}{ Q4 (n 414) } & \multicolumn{2}{|c|}{ Q5 (n 411) } & \multirow[b]{2}{*}{$P^{*}$} \\
\hline & Mean & SD & Mean & SD & Mean & SD & Mean & SD & Mean & SD & \\
\hline$M g$ from diet $(\mathrm{mg} / \mathrm{d})$ & 134 & 34 & 179 & 46 & 207 & 43 & 262 & 42 & 371 & 45 & $<0.0001$ \\
\hline Mg from supplementation (mg/d) & 9 & 23 & 43 & 46 & 71 & 41 & 45 & 40 & 83 & 35 & $<0.0001$ \\
\hline Total $\mathrm{Mg}$ intake $(\mathrm{mg} / \mathrm{d})$ & 144 & 34 & 225 & 17 & 281 & 15 & 338 & 19 & 454 & 76 & $<0.0001$ \\
\hline Age (years) & $59 \cdot 2$ & $8 \cdot 7$ & $60 \cdot 0$ & 8.9 & 61.4 & $8 \cdot 7$ & $61 \cdot 1$ & 8.9 & 61.3 & 8.9 & 0.01 \\
\hline \multicolumn{12}{|l|}{ Nutritional parameters } \\
\hline Energy intake (kJ/d) & 3753 & 1100 & 4556 & 1510 & 4987 & 1473 & 5971 & 1682 & 7544 & 2247 & $<0.0001$ \\
\hline Energy intake (kcal/d) & 897 & 263 & 1089 & 361 & 1192 & 352 & 1427 & 402 & 1803 & 537 & $<0.0001$ \\
\hline $\mathrm{Ca}$ intake $(\mathrm{mg} / \mathrm{d})$ & 771 & 465 & 1036 & 479 & 1266 & 460 & 1477 & 497 & 1722 & 547 & $<0.0001$ \\
\hline $\mathrm{K}(\mathrm{mg} / \mathrm{d})$ & 1408 & 400 & 4867 & 517 & 2145 & 492 & 2675 & 542 & 3689 & 833 & $<0.0001$ \\
\hline Vitamin D intake $(\mathrm{mg} / \mathrm{d})$ & 164 & 137 & 336 & 199 & 476 & 198 & 536 & 202 & 631 & 207 & $<0.0001$ \\
\hline Alcohol intake $(\mathrm{g} / \mathrm{d})$ & 4.1 & $7 \cdot 1$ & 3.8 & 6.4 & 3.8 & $5 \cdot 7$ & 3.5 & $5 \cdot 7$ & $2 \cdot 7$ & 4.4 & 0.007 \\
\hline BMI $\left(\mathrm{kg} / \mathrm{m}^{2}\right)$ & 29.0 & $5 \cdot 2$ & 28.7 & $5 \cdot 2$ & $28 \cdot 7$ & 5.69 & $28 \cdot 3$ & $5 \cdot 2$ & $28 \cdot 3$ & $5 \cdot 2$ & 0.28 \\
\hline \multicolumn{12}{|l|}{ Demographics } \\
\hline White race & \multirow{2}{*}{\multicolumn{4}{|c|}{284}} & \multirow{2}{*}{\multicolumn{2}{|c|}{322}} & \multirow{2}{*}{\multicolumn{2}{|c|}{329}} & & & \multirow[t]{3}{*}{$<0.0001$} \\
\hline$n$ & & & & & & & & & \multicolumn{2}{|c|}{315} & \\
\hline$\%$ & \multicolumn{2}{|c|}{69} & \multicolumn{2}{|c|}{72} & \multicolumn{2}{|c|}{77} & \multicolumn{2}{|c|}{80} & & & \\
\hline Smoking (previous/current) & & & & & & & \multirow{2}{*}{\multicolumn{2}{|c|}{225}} & & & \multirow[t]{3}{*}{0.79} \\
\hline $\mathrm{n}$ & \multicolumn{2}{|c|}{218} & \multicolumn{2}{|c|}{236} & \multicolumn{2}{|c|}{235} & & & & & \\
\hline$\%$ & \multirow{2}{*}{\multicolumn{2}{|c|}{53}} & \multirow{2}{*}{\multicolumn{2}{|c|}{28}} & \multirow{2}{*}{\multicolumn{2}{|c|}{56}} & \multicolumn{2}{|c|}{55} & & & \\
\hline College & & & & & & & & & & & 0.44 \\
\hline$n$ & 10 & & 10 & & 10 & & 10 & & & & \\
\hline$\%$ & 2 & & 25 & & 26 & & 25 & & & & \\
\hline Yearly income $(<\$ 50000)$ & & & & & & & & & & & 0.29 \\
\hline$n$ & 20 & & 21 & & 22 & & 23 & & & & \\
\hline$\%$ & 5 & & 54 & & 56 & & $5 \varsigma$ & & & & \\
\hline PASE (points) & 147 & 76 & 155 & 747 & 152 & 78 & 157 & 79 & 155 & 76 & 0.37 \\
\hline Medical conditions and medicatio & & & & & & & & & & & \\
\hline Charlson co-morbidity score & 0.36 & 0.89 & 0.37 & 0.82 & 0.35 & 0.76 & 0.35 & 0.74 & 0.35 & 0.71 & $\begin{array}{l}0.99 \\
0.47\end{array}$ \\
\hline$n$ & 5 & & 7 & & 8 & & 11 & & & & \\
\hline$\%$ & 1. & & 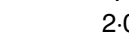 & & $2 \cdot 2$ & & 2. & & & & \\
\hline Bisphosphonates & & & & & & & & & & & 0.06 \\
\hline$n$ & 5 & & 61 & & 86 & & 73 & & & 6 & \\
\hline$\%$ & 13 & & 14. & & 20 . & & 17 & & & 6 & \\
\hline
\end{tabular}

Q, quintile; PASE, Physical activity Scale for Elderly.

${ }^{*} P$ values were calculated using the ANOVA for continuous variables and the $x^{2}$ test for categorical ones, respectively. Bonferroni correction was applied for all comparisons.

When divided by the RDA, only women reaching the RDA for $\mathrm{Mg}$ had a significant reduction in fracture risk of $27 \%(95 \% \mathrm{CI}$ $0.51,0.98, P=0.04)$.

On the contrary, total $\mathrm{Mg}$ intake, modelled as continuous variable, was not associated with any decreased risk for having fracture at follow-up (for $10 \mathrm{mg}$ increase in $\mathrm{Mg}$ intake: HR 1.00; $95 \%$ CI $0.97,1.03, P=0.99$ in men and HR 0.99; $95 \%$ CI 0.96 , $1.02, P=0.55$ in women).

\section{Discussion}

In this study, higher dietary $\mathrm{Mg}$ intake was associated with a significant reduction in fracture risk over 8 years of follow-up. Those having the highest $\mathrm{Mg}$ intake, in fact, reported a significant reduction of in fracture risk of $53 \%$ in men and of $62 \%$ in women, after adjusting for fourteen potential baseline confounders. However, the association between $\mathrm{Mg}$ intake and the onset of fractures seems to be stronger in women as only women reaching the RDA showed a significantly lower risk for fractures and only in women, after adjusting for height, did the association between $\mathrm{Mg}$ intake and fractures remain significant.
As shown at baseline, the prevalence of low $\mathrm{Mg}$ intake is very high, as only a quarter of the participants of OAI reported sufficient intake of $\mathrm{Mg}$. These data are in line with other studies showing a prevalence of $\mathrm{Mg}$ intakes lower than RDA reaching $75 \%^{(19,20)}$. Low $\mathrm{Mg}$ intake seems to predispose people to several medical conditions including metabolic diseases ${ }^{(5,6)}, \operatorname{CVD}^{(3,4)}$ and musculoskeletal diseases (e.g. sarcopenia) ${ }^{(21)}$.

Conversely, the data on $\mathrm{Mg}$ intake and fracture/osteoporosis risk are less clear. As mentioned in the 'Introduction' section, several studies and a recent meta-analysis reported contrasting findings on the association between $\mathrm{Mg}$ intake and fractures ${ }^{(9,10)}$. Our research is, to the best of our knowledge, the first reporting a clear and significant association between higher $\mathrm{Mg}$ intake and reduction in fractures in both sexes.

Several explanations support a role for $\mathrm{Mg}$ in preventing osteoporosis and fractures. First, $\mathrm{Mg}$ seems to be of relevance in bone health, positively affecting the function of osteoblasts and osteoclasts, and modulating Ca homoeostasis, through a regulation of calcitriol and the parathyroid hormone $^{(22)}$. Moreover, Mg stabilises amorphous Ca phosphate, slowing its transformation to hydroxyapatite ${ }^{(23)}$ and making 
Table 3. Association between baseline magnesium intake and incident fractures (Hazard ratios (HR) and $95 \%$ confidence intervals)

\begin{tabular}{|c|c|c|c|c|c|c|c|c|c|c|c|c|c|c|}
\hline \multirow[b]{3}{*}{ Mg intake } & \multicolumn{7}{|c|}{ Men } & \multicolumn{7}{|c|}{ Women } \\
\hline & \multirow[b]{2}{*}{ Cases } & \multirow[b]{2}{*}{ Subjects } & \multicolumn{2}{|c|}{ Incidence rate } & \multirow[b]{2}{*}{$\mathrm{HR}^{*}$} & \multirow[b]{2}{*}{$95 \% \mathrm{Cl}$} & \multirow[b]{2}{*}{$P$} & \multirow[b]{2}{*}{ Cases } & \multirow[b]{2}{*}{ Subjects } & \multicolumn{2}{|c|}{ Incidence rate } & \multirow[b]{2}{*}{$\mathrm{HR}^{*}$} & \multirow[b]{2}{*}{$95 \% \mathrm{Cl}$} & \multirow[b]{2}{*}{$P$} \\
\hline & & & Rate & $95 \% \mathrm{Cl}$ & & & & & & Rate & $95 \% \mathrm{Cl}$ & & & \\
\hline Q1 & 42 & 316 & 27 & 18,36 & 1 & Ref. & & 78 & 414 & 31 & 23,39 & 1 & Ref. & \\
\hline Q2 & 26 & 314 & 13 & 9,18 & 0.53 & $0.31,0.90$ & 0.02 & 73 & 411 & 30 & 22,38 & 0.77 & $0.52,1.14$ & 0.20 \\
\hline Q3 & 34 & 316 & 18 & 10,25 & 0.56 & $0.33,0.97$ & 0.04 & 74 & 421 & 28 & 20,36 & 0.62 & $0.39,0.99$ & 0.05 \\
\hline Q4 & 44 & 315 & 22 & 15,29 & 0.65 & $0.36,1.17$ & 0.15 & 76 & 414 & 36 & 25,47 & 0.56 & $0.32,0.98$ & 0.04 \\
\hline Q5 & 52 & 316 & 20 & 13,27 & 0.47 & $0.21,1.00$ & 0.05 & 61 & 411 & 27 & 20,34 & 0.38 & $0.17,0.82$ & 0.01 \\
\hline
\end{tabular}

Q, quintile; Ref, referent value.

* Fully adjusted hazard ratios included as covariates: age (as continuous); total energy intake (as continuous); race (white $v$. others); BMI (as continuous); education (college $v$. others); smoking habits (current $v$. previous/never); yearly income ( $\geq v$. $<\$ 50000$ or missing data;); Charlson co-morbidity index; use of drugs affecting positively bone (bisphosphonates, hormones, teriparatide); Ca intake (mg/d); K (mg/d); vitamin D intake (mg/d); alcohol intake (\% of total energy intake); Physical Activity Scale for the Elderly (as continuous).

(a)

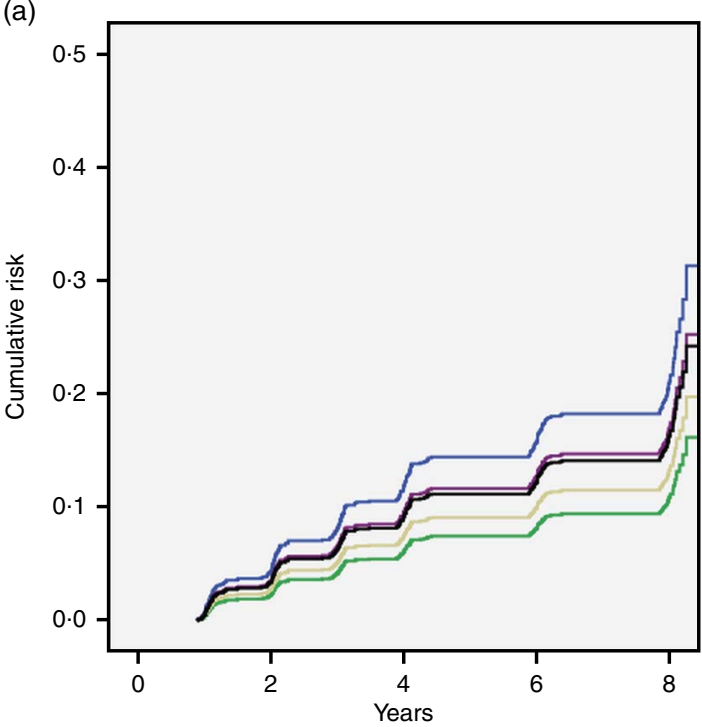

(b)

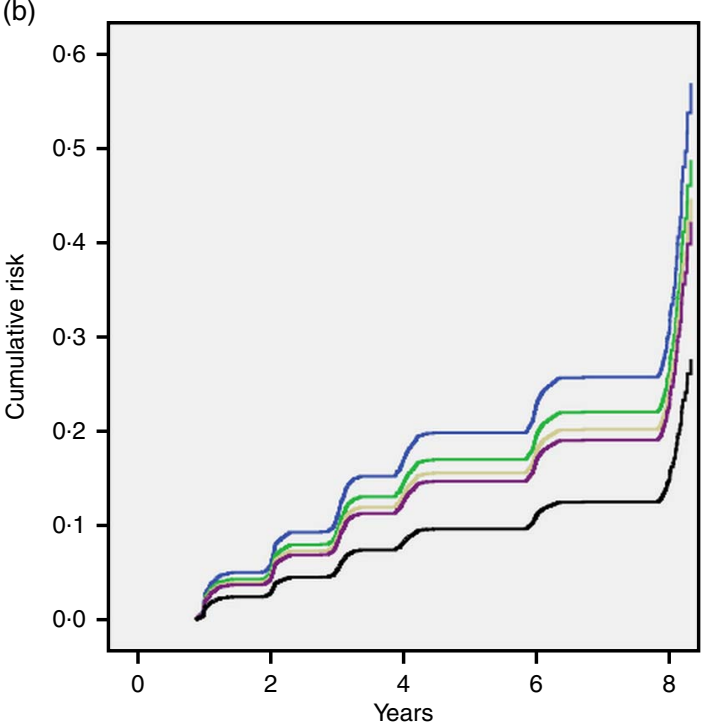

Fig. 1. Cumulative risk for any fracture at follow-up by magnesium intake at baseline in men (a) and women (b). Q, quintile; $\_$, Q1; $\_$, Q2; $\square$, Q3; $\neg$, Q4; ـ , Q5.

bones stronger. In osteoporotic women, low $\mathrm{Mg}$ and high hydroxyapatite content has been more commonly shown in the trabecular bone ${ }^{(24)}$.

Other effects, however, could contribute to the positive role of $\mathrm{Mg}$ on bone. First, $\mathrm{Mg}$ has an anti-inflammatory action ${ }^{(25)}$ and inflammation is a chronic condition leading to osteoporosis and fractures ${ }^{(26)}$. Second, $\mathrm{Mg}$ seems to be an essential element supporting muscular strength ${ }^{(21,27)}$ and consequently reduces the risk for falls and finally fractures.

The effect of $\mathrm{Mg}$ on fractures was more important in women than in men. It is known that women, particularly after menopause, have a decreased intake of micronutrients than men ${ }^{(28)}$ making them more sensitive to the consequences of nutritional deficiencies. Curiously, the other investigations regarding $\mathrm{Mg}$ and fractures were made in women, whereas the data in men are reported only by two studies showing no association between $\mathrm{Mg}$ intake and fractures ${ }^{(29,30)}$. However, more research is needed to understand why the association between $\mathrm{Mg}$ and fractures is less consistent in men.
The findings of our study should be interpreted within its limitations. First, dietary $\mathrm{Mg}$ intake was estimated only at baseline. Therefore, we cannot know if the changes in dietary patterns could affect our results. Second, the information regarding fractures and other medical conditions were only self-reported. Even if several studies ${ }^{(31,32)}$ reported that for major osteoporotic fractures the accuracy of self-reported fractures is as accurate as radiological records, we cannot exclude an underestimation of some non-clinical fractures, such as vertebral ones. Third, no data on BMD assessments are available and this could introduce another bias in our findings. Fourth, we were not able to run analyses for specific fracture sites due to a likely lack of power for these analyses. Finally, the OAI included participants with knee osteoarthritis or those at a high risk for this condition. Thus, a selection bias cannot be excluded and the generalisability of our findings in other contexts should be verified. Conversely, among the strengths of our work, we can include the large sample size of men and women as well as the long follow-up period of observation. 
In conclusion, higher dietary $\mathrm{Mg}$ intake has a protective effect on bone osteoporotic fractures, particularly in women, suggesting an important role of this mineral in osteoporosis and fractures. Further randomised controlled trials are needed to understand the possible role of $\mathrm{Mg}$ in delaying fractures.

\section{Acknowledgements}

The OAI is a public-private partnership comprised of five contracts (N01-AR-2-2258; N01-AR-2-2259; N01-AR-2-2260; N01-AR-2-2261; N01-AR-2-2262) funded by the National Institutes of Health, a branch of the Department of Health and Human Services, and conducted by the OAI Study Investigators. Private funding partners include Merck Research Laboratories; Novartis Pharmaceuticals Corporation, GlaxoSmithKline; and Pfizer, Inc. Private sector funding for the OAI is managed by the Foundation for the National Institutes of Health. This manuscript was prepared using an OAI public use data set and does not necessarily reflect the opinions or views of the OAI investigators, the National Institutes of Health or the private funding partners. The sponsors had no role in the design, methods, subject recruitment, data collection, analysis or preparation of this paper.

N. V. and M. N. analysed the data; B. S., M. S. and J. D. wrote the manuscript; A. V. and S. M. revised the manuscript. All authors approved the final version of this manuscript.

None of the authors has any conflicts of interest to declare.

\section{References}

1. Swaminathan R (2003) Magnesium metabolism and its disorders. Clin Biochem Rev 24, 47-66.

2. Veronese N, Zanforlini BM, Manzato E, et al. (2015) Magnesium and healthy aging. Magnes Res 28, 112-115.

3. Del Gobbo LC, Imamura F, Wu JHY, et al. (2013) Circulating and dietary magnesium and risk of cardiovascular disease: a systematic review and meta-analysis of prospective studies. Am J Clin Nutr 98, 160-173.

4. Mizushima S, Cappuccio FP, Nichols R, et al. (1998) Dietary magnesium intake and blood pressure: a qualitative overview of the observational studies. J Hum Hypertens 12, 447-453.

5. Sarrafzadegan N, Khosravi-Boroujeni H, Lotfizadeh M, et al. (2016) Magnesium status and the metabolic syndrome: a systematic review and meta-analysis. Nutrition $\mathbf{3 2}$, 409-417.

6. Dong J-Y, Xun P, He K, et al. (2011) Magnesium intake and risk of type 2 diabetes: meta-analysis of prospective cohort studies. Diabetes Care 34, 2116-2122.

7. Castiglioni S, Cazzaniga A, Albisetti W, et al. (2013) Magnesium and osteoporosis: current state of knowledge and future research directions. Nutrients $\mathbf{5}, 3022-3033$.

8. Farsinejad-Marj M, Saneei P \& Esmaillzadeh A (2016) Dietary magnesium intake, bone mineral density and risk of fracture: a systematic review and meta-analysis. Osteoporos Int 24, 1389-1399.

9. Orchard TS, Larson JC, Alghothani N, et al. (2014) Magnesium intake, bone mineral density, and fractures: results from the Women's Health Initiative Observational Study. Am J Clin Nutr 99, 926-933.
10. Michaelsson K, Holmberg L, Mallmin H, et al. (1995) Diet and hip fracture risk: a case-control study. Study Group of the Multiple Risk Survey on Swedish Women for Eating Assessment. Int J Epidemiol 24, 771-782.

11. Dibaba DT, Xun P \& He K (2014) Dietary magnesium intake is inversely associated with serum C-reactive protein levels: meta-analysis and systematic review. Eur J Clin Nutr 69, 3007

12. Hasebe N (2005) Oxidative stress and magnesium. Clin Calcium 15, 194-202.

13. Haring B, Crandall CJ, Wu C, et al. (2016) Dietary patterns and fractures in postmenopausal women. JAMA Intern Med 176, 645-652.

14. Willett WC, Howe GR \& Kushi L (1997) Adjustment for total energy intake in epidemiologic studies. Am J Clin Nutr $\mathbf{6 5}$, 1220S-1228S.

15. Katz JN, Chang LC, Sangha O, et al. (1996) Can comorbidity be measured by questionnaire rather than medical record review? Med Care 34, 73-84.

16. Washburn RA, McAuley E, Katula J, et al. (1999) The physical activity scale for the elderly (PASE): evidence for validity. J Clin Epidemiol 52, 643-651.

17. Food and Nutrition Board \& Institute of Medicine (1997) Dietary Reference Intakes for Calcium, Phosphorus, Magnesium, Vitamin D, and Fluoride. New York: Food and Nutrition Board \& Institute of Medicine.

18. Moayyeri A, Luben RN, Bingham SA, et al. (2007) Measured height loss predicts fractures in middle-aged and older men and women: the EPIC-Norfolk prospective population study. I Bone Miner Res 23, 425-432.

19. Beer-Borst S, Hercberg S, Morabia A, et al. (2000) Dietary patterns in six European populations: results from EURALIM, a collaborative European data harmonization and information campaign. Eur J Clin Nutr 54, 253-262.

20. Galan P, Preziosi P, Durlach V, et al. (1997) Dietary magnesium intake in a French adult population. Magnes Res 10, 321-328.

21. Veronese N, Berton L, Carraro S, et al. (2014) Effect of oral magnesium supplementation on physical performance in healthy elderly women involved in a weekly exercise program: a randomized controlled trial. Am J Clin Nutr $\mathbf{1 0 0}$, 974-981.

22. Nieves JW (2014) Bone. Maximizing bone health - magnesium, BMD and fractures. Nat Rev Endocrinol 10, $255-256$

23. Blumenthal NC, Betts F \& Posner AS (1977) Stabilization of amorphous calcium phosphate by Mg and ATP. Calcif Tissue Int 23, 245-250.

24. Manicourt DH, Orloff S, Brauman J, et al. (1981) Bone mineral content of the radius: good correlations with physicochemical determinations in iliac crest trabecular bone of normal and osteoporotic subjects. Metabolism 30, 57-62.

25. Nielsen FH (2014) Effects of magnesium depletion on inflammation in chronic disease. Curr Opin Clin Nutr Metab Care 17, 525-530.

26. Loi F, Córdova LA, Pajarinen J, et al. (2016) Inflammation, fracture and bone repair. Bone 86, 119-130.

27. Dominguez LJ, Barbagallo M, Lauretani F, et al. (2006) Magnesium and muscle performance in older persons: The InCHIANTI study. Am J Clin Nutr 84, 419-426.

28. Bolzetta F, Veronese N, De Rui M, et al. (2015) Are the recommended dietary allowances for vitamins appropriate for elderly people? J Acad Nutr Diet 115, 1789-1797.

29. Hayhoe RPG, Lentjes MAH, Luben RN, et al. (2015) Dietary magnesium and potassium intakes and circulating magnesium are associated with heel bone ultrasound attenuation and 
osteoporotic fracture risk in the EPIC-Norfolk cohort study. Am J Clin Nutr 102, 376-384.

30. Key TJ, Appleby PN, Spencer EA, et al. (2007) Calcium, diet and fracture risk: a prospective study of 1898 incident fractures among 34696 British women and men. Public Health Nutr 10, 1314-1320.
31. Ivers RQ, Cumming RG, Mitchell P, et al. (2002) The accuracy of self-reported fractures in older people. J Clin Epidemiol $\mathbf{5 5}$, 452-457.

32. Øyen J, Torstveit MK \& Sundgot-Borgen J (2009) Self-reported versus diagnosed stress fractures in Norwegian female elite athletes. J Sport Sci Med 8, 130-135. 